\title{
MODERATE EPISTEMIC AKRASIA
}

\author{
Nicolás Lo GuERcio \\ Universidad de Buenos Aires \\ CONICET \\ nicolasloguercio@gmail.com
}

SUMMARY: Moderate epistemic akrasia is the state a subject is in when she believes that $p$ and suspends judgment about whether her evidence supports $p$. In this article it is argued that, given a certain understanding of the attitude of suspension of judgment, moderate epistemic akrasia is doxastically irrational. The paper starts with a brief introduction that makes explicit some background notions and clarifies the dialectics of the debate. Second, the well-known distinction between propositional and doxastic rationality is introduced and some cases of improper basing are discussed (Turri 2011). Third, two different cases are considered in which one might argue that moderate epistemic akrasia is doxastically rational, and it is argued that none is successful. Fourth, several objections are presented and answered. Finally, some conclusions are drawn.

KEY WORDS: suspension of judgment, higher-order evidence, doxastic rationality, propositional rationality, epistemic basing relation

RESUMEN: Un agente está en un estado de akrasia epistémica moderada cuando cree que $p \mathrm{y}$, simultáneamente, suspende el juicio sobre si su evidencia apoya $p$. En este artículo se argumenta que, dada cierta manera de entender la suspensión del juicio, un agente moderadamente acrático es doxásticamente irracional. En primer lugar, se introducen ciertos conceptos básicos para el argumento y se discute la dialéctica del debate. En segundo lugar, se elabora la conocida distinción entre racionalidad doxástica y racionalidad proposicional, y se discuten algunos casos de fundación impropia desarrollados por Turri (2011). En tercer lugar, se consideran dos posibles casos a partir de los cuales podría argumentarse que la akrasia epistémica moderada es doxásticamente racional y se argumenta que ninguno de ellos funciona. En cuarto lugar, se examinan varias objeciones a la propuesta.

PALABRAS CLAVE: suspensión del juicio, evidencia de segundo orden, racionalidad doxástica, racionalidad proposicional, relación de fundación epistémica

\section{Preliminaries}

Radical epistemic akrasia is the state a subject is in when she believes $p$ and she believes that her evidence does not support $p .^{l}$ Whether

${ }^{1}$ Following Greco (2013), I stipulate the following formulations to be equivalents to the one above motioned: "it is rational for an agent to believe $p$ and it is rational for her to believe that it is not rational for her to believe $p$ ", "one ought to believe $p$, but one ought to believe that one ought not believe $p$ ", "one should believe $p$, but one should believe that one should not believe $p$ ", "one has justification to believe $p$, but one has justification to believe that one doesn't have justification to believe $p$ " or 
there are possible circumstances in which it is rational to be radically akratic is controversial: although many epistemologists vindicate a "non-akrasia constraint" on rationality, there have been some noteworthy defenses of the opposite view. ${ }^{2}$ There is also a moderate form of epistemic akrasia which consists in believing $p$ while simultaneously suspending judgment about whether the evidence supports $p$. Whether moderate epistemic akrasia can be rational is also controversial. ${ }^{3,4}$

The foregoing considerations regarding about radical and moderate epistemic akrasia concern propositional rationality. ${ }^{5}$ An attitude is propositionally rational for an agent if and only if the agent has sufficient evidence in support of that attitude. Thus understood, the problem is whether there are any possible circumstances that make it rational for an agent either a) to believe $p$ and to believe that it is not rational for her to believe $p$ (radical epistemic akrasia) or b) to suspend judgment about whether it is rational for her to believe $p$ and to believe $p$ (moderate epistemic akrasia).

Cases of epistemic akrasia, however, also raise worries concerning doxastic rationality. Doxastic rationality is traditionally thought of as propositional rationality plus basing: an attitude is doxastically rational for an agent if and only if the agent has sufficient evidence to hold the attitude and she holds the attitude based on the evidence that makes it rational for her to hold it. In this regard, one might wonder whether there are any possible circumstances in which an agent a) rationally believes $p$ and rationally believes it is not rational for her to believe $p$ (radical epistemic akrasia), or b) rationally suspends judgment about whether believing $p$ is rational for her and rationally believes $p$ (moderate epistemic akrasia). These questions concerning propositional and doxastic rationality are interrelated. In particular, if epistemic akrasia is not propositionally rational then it's not doxastically rational either, since the latter requires the former. By contrast, if epistemic akrasia is sometimes propositionally ratio-

"It is reasonable to believe $p$, but it is reasonable to believe that it is not reasonable to believe $p$ ".

${ }^{2}$ See Coates 2012, Wedgwood 2012 and Weatherson unpublished manuscript (2010).

${ }^{3}$ For a defense of rational moderate epistemic akrasia see Hazlett 2012. Feldman 2005, Huemer 2011, and Bergmann 2005 argue for the opposite view.

${ }^{4}$ These two problems are independent, i.e. one might place a non-radical akrasia constraint upon rationality but allow for rational moderate forms of epistemic akrasia, see Hazlett 2012.

${ }^{5}$ See Horowitz 2014 and Titelbaum 2015. 
nal, that is consistent either with maintaining that epistemic akrasia is sometimes doxastically rational or with claiming that epistemic akrasia is never doxastically rational.

In this article I will focus on doxastic rationality in relation with moderate cases of epistemic akrasia. Concretely, I'll argue that moderate epistemic akrasia is not doxastically rational, even if we assume for the sake of the argument that it is propositionally rational.

The paper is structured as follows. First, I will make the idea of moderate epistemic akrasia more precise by disambiguating the notion of "suspension of judgment" involved in it. Second, I'll discuss Turri's idea (2010) of improper basing. Third, I'll examine what I consider the most plausible cases that might be put forward in favor of the claim that moderate epistemic akrasia is sometimes doxastically rational and I'll argue that none is successful. Fourth, I will tackle a number of objections that might be raised against the view here defended, before drawing some conclusions.

\section{Setting the Stage}

Moderate epistemic akrasia involves the attitude of suspension of judgment. So before discussing whether it can be rational it is necessary to be clear about what kind of attitude suspension of judgment is. As Friedman (2013) notes, there are two kinds of accounts of suspension of judgment: the non-belief accounts and the attitudinal accounts. According to Non-Belief accounts suspension of judgment about $p$ has to do with the lack of an attitude towards $p$. The core idea of these views is that for a subject to suspend judgment regarding a proposition $p$ at a time $t$, it is necessary that she neither believes nor disbelieves $p$ at $t .^{6}$ This is not sufficient, though. Defenders of NonBelief accounts usually impose further requirements on suspension of judgment, e.g. having considered the matter, having epistemic reasons for not believing, and so on. Attitudinal accounts, on the other hand, maintain that suspension of judgment is an attitude that expresses a committed state of neutrality or indecision on the part of the agent regarding some proposition; in other words, within these accounts suspension of judgment is thought of as an attitude that expresses the indecision or neutrality of the agent as to the truth of $p .^{7}$

${ }^{6}$ Let's call the state that $S$ is in when he has no $p$-belief and no $\neg p$-belief, a state of non-belief with respect to $p$ (or a state of $p$-non-belief). We can call the particular kind of non-attitude account of agnosticism suggested by Chisholm (and others), a "non-belief account" (Friedman 2013, p. 2).

${ }^{7}$ There are also several options within attitudinal accounts, see for example Crawford 2004 and Friedman 2013. 
It is clear that what we mean by "moderate epistemic akrasia" depends in part on what we mean by "suspension of judgment". Being moderately akratic might involve holding no attitudes regarding whether the evidence supports $p$ (plus some additional requirement, e.g. having considered the matter) or, in turn, holding an attitude that expresses a state of committed neutrality or indecision regarding whether the evidence supports $p$.

It is not the aim of this article to adjudicate the debate between non-belief and attitudinal accounts of suspension of judgment. It will be enough to state explicitly which approach will be pursued, to motivate this decision and to say something about the alternative option. I will assume that suspension of judgment concerning $p$ consists in holding a particular attitude of committed neutrality as to the truth of $p$, i.e. I will assume an attitudinal account. This decision is partly motivated by the fact that some of my potential opponents, i.e. defenders of rational epistemic akrasia (viz. Hazlett 2012) understand suspension of judgment in this way. ${ }^{8}$ The idea is to argue against the possibility of doxastically rational moderate epistemic akrasia given the same background assumptions. Admittedly, however, one might want to adopt a non-belief approach. If one goes in that direction, I have no qualms in conceding that moderate epistemic akrasia (thus understood) might be doxastically rational (provided it be propositionally rational). An agent that suspends judgment about $p$ in the non-belief sense does not have any opinion regarding the epistemic status of her first-order belief (even if she has considered the matter), so I see no reason to maintain that she cannot rationally believe $p$, unless one endorses the contentious view (which I do not endorse) according to which rationally believing a proposition requires that you rationally believe that it is rational for you to believe that proposition. ${ }^{9}$

A second clarification is in order. I've been talking (and I will continue on that path) interchangeably in terms of rationality and in terms of evidence. Thus, it might be thought that my arguments only work if one assumes an evidentialist view, thus a mentalist/internalist view about rationality. I will discuss this worry in detail in section 5 .

8 "And I assume suspension of judgment about $p$ is an attitude towards $p$; it is distinct from taking no attitude towards $p$, and distinct from neither believing nor disbelieving" (Hazlett 2012, p. 206).

${ }^{9}$ This is something like the JJ-principle that, according to some internalists, is a necessary condition for justification. I am not committed to the JJ-principle or its equivalent in terms of rationality, and my view does not require accepting an internalist approach to rationality. I will argue for this in detail in section 5 . 
For now, let me just note that moderate epistemic akrasia could be defined using neutral vocabulary in the following way. Call $X$ whatever condition is required for a belief to be rational. $X$ could be your reflectively accessible mental states, the fact that your belief was formed by a reliable belief-forming process, the fact that it is part of a coherent set of beliefs, etc. A moderately akratic agent is someone who believes $p$ and suspends judgment about whether $X$ is satisfied. If you assume the view that a belief is rational only if it is the output of a reliable belief-forming process then an akratic agent is someone who believes $p$ and reliably suspends judgment about whether her belief that $p$ was reliably formed. If you favor the view that a belief is rational for a subject if and only if it is supported by the evidence she has at the time, then being moderately akratic consists in believing $p$ and suspending judgment about whether $p$ is supported by the evidence. Although I will present my view in terms of evidence, the arguments I will provide do not depend on this in order to work: they could be formulated in the neutral way aforementioned.

\section{Doxastic Rationality}

As stated in the introduction, I will focus on doxastic rationality. Now, recent work on the relation between doxastic and propositional rationality has brought into attention a possible kind of mismatch between the two, one that will turn out to be relevant to our problem. ${ }^{10}$ These are examples in which it is rational for $S$ to believe that $p$ and $S$ believes that $p$ based on the evidence that makes it rational for her to believe that $p$, and yet she does not rationally believe that $p$, on account of her belief not being properly based. Here is Turri's example (2010, p 317). Suppose that Mr. Ponens and Mr. F.A. Lacy each knows the following things:

(P1) The Spurs will win if they play the Pistons.

(P2) The Spurs will play the Pistons

From these two premises and only these premises, each concludes

(P3) Therefore, the Spurs will win.

${ }^{10}$ Cf. Turri 2010 and Silva 2015. Turri and Silva use "justification" instead of "rationality", I'm using them interchangeably in this context. 
However, while Mr. Ponens applies modus ponens to reach (P3), Mr. F.A. Lacy arrives at the conclusion by means of a different rule, modus profusus, according to which for any $p, q$, and $r:(p \& q) \rightarrow$ $r$. Intuitively, both subjects believe (P3) and each bases his belief on the reasons that make it rational for him to believe it. However, only Mr. Ponens rationally believes that the Spurs will win. The moral that should be extracted from the example is that there is something more to doxastic rationality than just propositional rationality plus basing.

The missing element concerns "the way in which an agent performs in forming or sustaining a belief" (Turri 2010, p. 315) [my emphasis]:

In evaluating beliefs we are evaluating a kind of performance, the performance of a cognitive agent in representing the world as being a certain way, and when performing with materials (which, in cognitive affairs, will include reasons or evidence), the success, or lack thereof, of one's performance will depend crucially on the way in which one makes use of those materials. (p. 315)

The way in which the subject performs, the manner in which she makes use of her reasons, fundamentally determines whether her belief is doxastically justified. Poor utilization of even the best reasons for believing $p$ will prevent you from justifiably believing or knowing that p. (p. 318)

The moral is that we should revise the standard view of doxastic rationality: basing your attitudes on good evidence is not sufficient for doxastic rationality, in addition you must base your beliefs properly.

As I anticipated, the idea of improper basing will be significant in the arguments to come. However, it is important to note that I do not wish to maintain that cases of moderate epistemic akrasia are exactly analogous to Turri's case. Mr. F.A. Lacy exemplifies only one way in which one can base one's beliefs improperly. ${ }^{11}$ In the next section, I will discuss a different way in which one might perform poorly, thus making place for a different way in which one's beliefs might be improperly based.

One final caveat before getting to the point. As I said, in this article I'll focus on alleged cases of doxastically rational moderate epistemic akrasia. These cases involve a subject rationally suspending judgment about the epistemic status of her first-order evidence. Now,

\footnotetext{
${ }^{11}$ Turri himself presents another case of improper basing in which the source of inappropriateness is different, see Turri 2010, pp. 315-316.
} 
since propositional rationality is a necessary condition for doxastic rationality, these are also cases in which it is propositionally rational for the subject to suspend judgment about whether her first-order evidence supports $p$, i.e. cases in which higher-order suspension of judgment is supported by higher-order evidence. ${ }^{12}$ The question then arises: in what circumstances is it rational for a subject to suspend judgment about whether it is rational for her to believe a proposition? ${ }^{13}$ In other words, in what circumstances does higher-order evidence support higher-order suspension of judgment concerning the epistemic status of first-order evidence?

There are two views in that regard. On one view, higher-order suspension of judgment is rational only if the agent possesses higherorder evidence that supports her being undecided about whether her first-order evidence supports $p$. That is, she has evidence that makes it equally likely that the first-order evidence supports $p$ and that it supports $\sim p$. In this case it seems to be rational to be undecided about the epistemic status of the first-order evidence, that is, to suspend judgment about it. The second view has been proposed by Feldman (2005). ${ }^{14}$ According to Feldman's view, $S$ 's higher-order evidence supports $S$ 's higher-order suspension of judgment about whether it is rational for her to believe $p$ only if $S$ 's higher-order evidence indicates that $S$ 's first-order evidence supports neither $p$ nor $\sim p .^{15}$

${ }^{12}$ By "higher-order evidence" I mean evidence concerning the existence or the significance of first-order evidence.

${ }^{13}$ One might wonder whether the evidence in these cases is always higher-order. Suppose I know that I have just taken drugs that cause hallucinations, and on that basis I suspend judgment about whether my current experiences of pink elephants support believing that there are pink elephants before me. That's higher-order suspension of judgment, but the basis doesn't seem "higher-order": it's just the proposition that I have just taken drugs that cause hallucinations. However, higherorder evidence is evidence concerning the existence or the significance of first-order evidence, and the proposition that I have just taken drugs that cause hallucinations is evidence of this type: it is evidence of a possible cognitive malfunction on my part, that is, it is evidence that I might have misjudged the significance of the evidence provided by my current experiences of pink elephants. I would like to thank a referee for Crítica for drawing my attention to this worry.

${ }^{14}$ Hazlett (2012, p. 208) also discusses Feldman's assumption: "The second assumption is that someone reasonably suspends judgment about whether her evidence supports $p$ only if her evidence indicates that her evidence supports neither $p$ nor not-p."

${ }^{15}$ It has been noted by an anonymous referee for Crítica that the former possibility is a counterexample to the latter. Even if this is true, I don't think it's a problem for my view since, if my arguments are successful, being moderately akratic 
To sum up the points made in sections 2 and 3: 1) I'll assume that suspension of judgment is an attitude of committed neutrality or indecision about a proposition; 2) following Turri, I will assume that the way in which an agent performs in forming or sustaining a belief can affect doxastic rationality and, more importantly, that there are many different ways in which one's beliefs might be improperly based; 3) I will consider two possible answers to the question of when an agent rationally suspends judgment about whether her first-order evidence supports a proposition: first, the view according to which rationally suspending judgment in the second-order requires that the agent possess higher-order evidence that supports her being committedly undecided about whether her first-order evidence supports $p$; second, the view that rationally suspending judgment involves the possession of higher-order evidence supporting that the first-order evidence supports neither $p$ nor $\sim p$.

\section{No Doxastic Rationality in Cases of Moderate Epistemic Akrasia}

Now we can get to our problem. The question was whether there are possible circumstances in which an agent rationally believes $p$ while rationally suspending judgment about whether it is rational for her to believe $p$. The scenario that needs consideration is the following: an agent, $S$, possesses evidence, $E$, concerning $p$, and $E$ in fact supports $p$. After thoroughly assessing the evidence, $S$ comes to believe that $p$. Later on $S$ obtains higher-order evidence that supports suspension of judgment about whether $E$ supports $p$. In light of this, $S$ suspends judgment about whether it is rational for her to believe that $p .{ }^{16}$

One can go in one of two directions here with regard to propositional rationality. On the one hand, one might claim that it is never propositionally rational to be moderately akratic, that is, that the total evidence can never make it propositionally rational for an agent both to suspend judgment about whether it is rational for her to believe $p$ and to believe $p$. Now, since doxastic rationality requires

is doxastically irrational in both cases. As long as my arguments work, they do so whatever turns out to be the correct account of higher-order suspension of judgment.

${ }^{16}$ One might imagine a different scenario in which the agent acquires the higherorder evidence first and obtains the first-order evidence later. In that case the problem is not whether she can rationally maintain her belief in light of the newly acquired higher-order evidence but whether it is rational for her to form the belief in the face of the newly acquired first-order evidence. I will tackle this worry in section 5 . 
propositional rationality, it follows from that view that it is never doxastically rational to be moderately akratic.

Admittedly, one might not be willing to grant that propositionally rational moderate epistemic akrasia is impossible. Let's assume then, for the sake of the argument, that moderate epistemic akrasia is sometimes propositionally rational. ${ }^{17}$ This assumption is consistent both with the idea that moderate epistemic akrasia is sometimes doxastically rational and its negation. Hereinafter I will argue for the latter.

The argument goes as follows. Assume that $S$ rationally suspends judgment about whether it is rational for her to believe $p$. Since doxastic rationality requires propositional rationality, it follows that it is rational for $S$ to suspend judgment about whether it is rational for her to believe $p$. We saw in the previous section that there are two different views about how this might happen. According to the first view, $S$ must possess higher-order evidence that supports being committedly undecided about whether her evidence supports $p$. If this condition is satisfied and $S$ suspends judgment about whether it is rational for her to believe $p$ based on the corresponding higherorder evidence, then $S$ rationally suspends judgment about whether it is rational for her to believe $p$. According to the second view, $S$ must have higher-order evidence supporting that her first-order evidence supports neither $p$ nor $\sim p$. If this condition is satisfied and $S$ suspends judgment about whether it is rational for her to believe $p$ based on the corresponding higher-order evidence, then $S$ rationally suspends judgment about whether it is rational for her to believe $p .^{18}$ In what follows I'll consider each possibility separately and I'll argue, in both cases, that $S$ cannot rationally believe $p$.

\subsection{Case 1}

On the first possibility $S$ s higher-order evidence supports being undecided about what her first-order evidence, $E$, supports. In light of this higher-order evidence, $S$ rationally suspends judgment about whether $E$ supports $p$. Is it possible for $S$ in this situation to rationally believe $p$ ? I'll argue that it's not.

To better see the point consider the following case, adapted from a case presented by Horowitz (2014):

\footnotetext{
${ }^{17}$ Hazlett (2012) and Coates (2012) defend this view.

${ }^{18}$ In what follows I will assume, in both cases, that the higher-order suspension of judgment is properly based.
} 
Sleepy Detective*: Sam is a police detective, working to identify a jewel thief. He knows he has good evidence - out of the many suspects, it will strongly support one of them. Late one night, after hours spent assessing all the evidence, he finally comes to the conclusion that the thief was Lucy. Sam is quite confident that his evidence points to Lucy's guilt, and he is quite confident that Lucy committed the crime. In fact, he has accommodated his evidence correctly, and his beliefs are rational. He calls his partner, Alex. "I've gone through all the evidence", Sam says, "and it all points to one person! I've found the thief!" But Alex is unimpressed. She replies: "I can tell you've been up all night working on this. But five times out of the last ten, your late-night reasoning has been quite sloppy. You're always very confident that you've found the culprit, but you're only half of the time right about what the evidence supports. So there is only a $50 \%$ chance your evidence supports Lucy in this case." Though Sam hadn't attended to his track record before, he rationally trusts Alex and believes that she is correct -i.e. that he is right only $50 \%$ of the times about what the evidence supports on occasions similar to this one.

Alex's testimony provides Sam evidence that indicates that it is equally likely that his evidence supports Lucy's guilt and that it supports her innocence (let's assume that since there is a presumption of innocence, if the evidence does not support Lucy's guilt it supports her innocence). In virtue of this, Sam rationally suspends judgment about whether his evidence supports Lucy's guilt. Now, suppose that despite this Sam continues believing that Lucy is guilty. Is it doxastically rational for Sam to maintain his belief?

I'll argue that the answer is "no". The problem is that in this situation Sam's belief that Lucy is the thief is improperly based, on account of being maintained arbitrarily. This is so despite the fact that his evidence supports Lucy's guilt and that he based his belief on that evidence. Schematically, the argument goes like this: as I'll argue, Sam's case involves some sort of arbitrariness. But believing arbitrarily is a certain kind of bad epistemic performance. Moreover, it is a kind of bad epistemic performance that might be present even though the subject has based her belief on good reasons. Now, by stipulation, Sam has based his belief on good reasons, so Sam's case is a case in which he bases his belief on good reasons but still performs poorly in forming beliefs. But this is just how we characterized improper basing in the foregoing paragraphs. Hence, Sam's case 
involves a kind of improper basing. Finally, since improper basing prevents beliefs from being doxastically rational, Sam's belief is not doxastically rational.

I motivated the above mentioned characterization of improper basing in section 2, and I do not think it is controversial that forming beliefs arbitrarily falls into the category of "bad epistemic performance", so ultimately the argument hinges on the premise that Sam is being in some sense arbitrary. Now, there is one sense of "arbitrariness" according to which believing arbitrarily consists just in believing without reasons. Admittedly, in this sense Sam's belief is not arbitrary; by stipulation he has good reasons to believe that Lucy is the thief. This sense of arbitrariness is what is at stake when assessing a belief in terms of propositional rationality. But as we said earlier doxastic rationality also involves an assessment of the way in which the subject performs in forming beliefs; assessing a belief for doxastic rationality thus requires considering a procedural dimension, and when assessing a belief from this point of view, it becomes relevant how things look from the subject's perspective.

With this in mind, we can say that what's arbitrary in Sam's epistemic performance is that he treats his evidence as supporting Lucy's guilt even though he consciously evaluated that he cannot determine whether such evidence is in fact indicative of Lucy's guilt, and moreover, even though he is committed to the idea that it is equally likely that his evidence supports Lucy's innocence. In other words, from Sam's perspective believing that Lucy is the thief and believing that she is not the thief are epistemically on a par. The arbitrariness in Sam's epistemic performance stems from the fact that although he considers both alternatives to be epistemically on a par, he proceeds as if they were not, i.e. as if one of them were better supported by the evidence than the other. From the procedural point of view that is relevant to doxastic rationality this is reproachable: in general, it is a bad epistemic policy to treat what seem to be equally good alternatives as if they were not.

Now, remember the lesson from Turri's work discussion: the way in which a subject performs can prevent her from being doxastically rational, even if she has based her belief on good reasons. Applying that lesson to this case: Sam proceeds arbitrarily by not treating in the same way what seem to him to be equally good alternatives. Hence, although he bases his belief that Lucy is the thief on good evidence, that belief is not doxastically rational, on account of being improperly based. 
A final comment: I grant that Sleepy Detective* is not exactly analogous to the Mr. F.A. Lacy case. In the latter, improper basing stems from the fact the subject makes use of an invalid inference rule when deducing the conclusion from the premises; in the former, the inappropriateness comes from the fact that the subject treats what looks to him as equally well supported beliefs as if they were not equally well supported. I don't think this is a problem though, since improper basing as a general phenomenon need not involve the use of an invalid inference rule: we can legitimately say that cases of moderate epistemic akrasia are cases of improper basing as long as they involve a kind of questionable epistemic performance on the part of the subject, and I think that being arbitrary in the sense previously discussed fits this description.

\subsection{Case 2}

On the second view earlier considered (Feldman's view), a subject, $S$, rationally suspends judgment about whether her evidence supports $p$ only if $S$ possesses higher-order evidence that supports that her first-order evidence supports neither $p$ nor $\sim p$. To illustrate the point consider the following case (adapted from Coates 2012):

HOLMES AND WATSON: Watson is a promising apprentice of Holmes, a master sleuth. As part of his training, Watson will often accompany Holmes to crime scenes and other locations, size up the evidence as best he can, and tell Holmes what conclusion he has drawn and how he has drawn it. Now suppose that Holmes brings Watson to a crime scene, assume that the evidence indicates that the butler is guilty, and that Watson uses good reasoning to arrive at that conclusion. In short, Watson rationally believes that the butler did it. Later, Holmes, after having assessed the evidence himself, tells Watson that in his opinion the evidence supports neither the butler's guilt nor his innocence. Authoritative though he is, Holmes is not infallible, and this is one of the rare occasions in which he is wrong. However, given that Holmes is a master sleuth Watson is rational in accepting his conclusion: Holmes's testimony on these matters is very authoritative.

Holmes's testimony provides Watson higher-order evidence that the first-order evidence supports neither the butler's guilt nor his innocence. Suppose then that in light of this evidence Watson rationally suspends judgment about the matter, in line with Feldman's 
view. Similar considerations concerning arbitrariness apply to this case. If Watson suspends judgment after hearing Holmes's testimony then he comes to think of his evidence as supporting neither the butler's guilt nor his innocence. That is, Watson considers both alternatives to be on a par. But then, on what grounds could he prefer one over the other? In other words: from Watson's perspective his evidence is as indicative of the butler's guilt as it is of his innocence, so believing that he is guilty (i.e. treating the evidence as if it were indicative of the butler's guilt) is arbitrary. Now, from the point of view of propositional rationality this is irrelevant: all that matters is that Watson has good reasons to maintain his belief. From the point of view of doxastic rationality, however, the way in which the agent bases her beliefs matters: in this case, the agent judges that there is no consideration licensing the conclusion that the butler did it (and to eliminate the other alternative), and still he maintains that belief. Since by believing arbitrarily Watson performs poorly, his belief is not properly based. In consequence, even if he bases his belief on good reasons he does not rationally believe that the butler is guilty.

Here's another way of putting the point. If Watson, after hearing Holmes's testimony, is committedly undecided about whether his evidence supports the butler's guilt or his innocence, and he continues nonetheless to believe the former, it seems that he is just guessing, and hoping to be lucky (even if, unknown to him, the evidence does happen to support the butler's guilt). To be clear, I am not saying that this is a case of epistemic luck; after all, by stipulation the evidence in fact supports the butler's guilt, so following the evidence will not lead Watson to the truth just by accident. However, it looks like a case of luck from Watson's perspective, in the sense that he maintains his belief despite consciously judging that in the face of his evidence the odds of holding a true belief by believing that the butler is guilty are no better than the odds of holding a true belief by believing that the butler is innocent. In other words, he retains his belief despite judging that the odds of getting to the truth in the face of his evidence are no better than chance. In general, this is a bad epistemic policy.

Now, on closer inspection intentional reliance on luck seems to be just another way of forming beliefs arbitrarily: the subject seems not to care about basing her beliefs on good enough reasons. This is bad enough to preclude Watson from properly basing his belief. In consequence, his belief that the butler is guilty is not doxastically rational. Thus, even if we admit that the overall evidence Watson possesses makes it rational for him to believe that the butler is guilty 
and he makes use of that evidence, we must conclude that Watson does not rationally believe $p$, on account of believing arbitrarily. ${ }^{19}$

As a final remark, let me address the following concern. As was mentioned in section 2 (see also fn. 8) I adopted an attitudinal account of suspension of judgment. I characterized this attitude as involving some sort of commitment to being neutral or undecided regarding some matter. One may worry that while this characterization of suspension of judgment is not mandatory (viz. there is room for an attitudinal view of suspension of judgment that does not ascribe any commitment to the subject) it is necessary for my argument to work: if higher-order suspension of judgment does not involve any commitment to being undecided, one could think, first-order belief will not look arbitrary to the subject. Moreover, not only is the notion of commitment avoidable in this context; it is also suspicious: after all the whole point of suspending judgment seems to be to avoid commitment.

First, one cannot just assume that the whole point of suspension of judgment is to avoid commitment. In fact, several philosophers working on the topic characterize suspension of judgment as involving a kind of commitment: Friedman argues for an attitudinal account of suspension of judgment, which she characterizes as an attitude of "committed indecision" (2013, fn. 5), while Sturgeon (2010) describes it as a kind of "committed neutrality". Also, in Crawford's view (2004) suspension of judgment is understood as a kind of higher-order belief, so it could also be plausibly described in terms of commitments. That being said, I concede that it might be possible to formulate an attitudinal account of suspension of judgment which does not characterize it in terms of commitments. But, to be sure, the onus of proof is on my opponents to show how such an account would go and that such a view is in fact tenable; and even if it is, it is not entirely clear how it would affect my arguments.

\section{Objections}

In this last section I will tackle several objections that might be raised against the view I've been defending. First, I will consider whether my view presupposes an internalist approach to rationality. Second, I will further motivate the idea that the subject's perspective is important to determine whether a belief is doxastically rational.

${ }^{19}$ As with Sleepy Detective*, this case is not exactly like Turri's Mr. F.A. Lacy case, but it can legitimately be called a case of improper basing since it involves a kind of poor epistemic performance on the part of the agent. 
Finally, I will consider whether there is a difference between cases of moderate epistemic akrasia in which one maintains a first-order belief after rationally suspending judgment on the second level and cases in which one forms a first-order belief after rationally suspending judgment on the second level.

\section{1. Internalism/Externalism}

One possible worry regarding the view proposed earlier is that it presupposes an internalist view about rationality or justification. ${ }^{20}$ If this were so, the scope of the argument would be very limited: it would leave those who advocate an externalist (or otherwise non-internalist) theory unmoved. However, I don't think the view I defended presupposes internalism. In this section I will explain why.

Internalist theories come in different flavors, but there is a core idea that underlies most of them, viz. in order for a belief to be justified or rational the subject must be aware (or potentially aware) of all (or at least some of) the reasons or justifiers for that belief. Bergmann states this condition as follows: ${ }^{21}$

The Awareness Requirement: $S$ 's belief $B$ is justified only if (i) there is something, $X$, that contributes to the justification of $B-$ e.g. evidence for $B$ or a truth-indicator for $B$ or the satisfaction of some necessary condition of $B$ 's justification- and (ii) $S$ is aware (or potentially aware) of $X$. (Bergmann 2006, p. 9)

As Bergmann notes, one of the most compelling motivations for this kind of internalist requirement comes from BonJour's famous case of Norman, the Clairvoyant (BonJour 1985, p. 41). Very roughly, according to BonJour whenever Norman is not aware of whatever makes his belief justified his belief looks accidental or arbitrary from his perspective, thus he is not justified. Of course, it might be that from an external point of view the belief would not look accidental or arbitrary, but according to BonJour it is his own perspective that matters. Bergmann summarizes this motivation as follows:

\footnotetext{
${ }^{20}$ Thanks to an anonymous referee for Crítica for suggesting that I should address this point.

${ }^{21}$ The correct way of characterizing internalism is a controversial matter itself, but I think the proposed characterization will be shared by many. Some philosophers, e.g. Conee and Feldman (2004), characterize internalism in a different way. I will be concerned with them below.
} 
The Subject's Perspective Objection: If the subject holding a belief isn't aware of what that belief has going for it, then she isn't aware of how its status is any different from a stray hunch or an arbitrary conviction. From that we may conclude that from her perspective it is an accident that her belief is true. And that implies that it isn't a justified belief. (Bergmann 2006, p. 12)

Admittedly, the arguments I developed in the previous sections exhibit some resemblance with BonJour's remarks. However, I'll argue that the view I defended is consistent with the rejection of both the awareness requirement and the subject's perspective objection. Hence, it does not presuppose internalism.

First, I'll argue that my view is consistent with the rejection of the awareness requirement. Let's call rationality-contributors whatever facts are relevant for the rationality of a belief. These facts might include the actual basis for a belief as well as facts about the obtaining of a support relation between that basis and the belief. Internalism about rationality is the idea that it is a necessary condition for a belief to be rational that the subject is aware (or potentially aware) of (at least some of) her rationality-contributors for that belief. Externalism, by contrast, contends that at least sometimes a belief can be rational even if the cognizer is not (or is incapable of being) aware of (at least some of) the rationality-contributors for her belief. It is worth noting that externalism is not the claim that agents are never aware of the rationality-contributors for their beliefs: it is compatible with externalism that agents are sometimes aware of the rationalitycontributors for their beliefs.

Now, in the previous sections I argued that if you rationally suspend judgment about the epistemic status of your first-order belief then such belief is not doxastically rational. It is plausible to assume that if you rationally suspend judgment about the epistemic status of your first-order belief then you must be aware of (at least some of) the rationality-contributors for that belief. However, what follows from this is that your actual awareness of the rationality-contributors for a belief $B$ might affect $B$ 's doxastic rationality. What doesn't follow is that your lack of awareness of the rationality-contributors for $B$ turns $B$ irrational (either doxastically or propositionally). It is one thing to say that when you are in fact aware of the rationality-contributors for $B$ this might affect $B$ 's rationality (according to my view, only insofar as you rationally suspend judgment regarding the obtaining of a support relation between the basis for $B$ and $B$ ), and another thing to say that it is a necessary condition for $B$ to be rational that 
you are aware of the rationality-contributors for $B$. I maintained the former, but this is consistent with rejecting the latter.

In order to illustrate the point consider the following example. Very roughly, reliabilism is the view that a belief is rational only if it is the output of a reliable belief-forming process, i.e. a process that is truth-conducive. Whether a belief is the output of a truth-conducive belief-forming process is not something to which agents typically have reflective access. However, reliabilism is compatible with adding some further requirement according to which in order for a belief to be rational one must not have a reliable belief that such a belief is not reliable. ${ }^{22}$ In the same way, one could add a negative requirement according to which in order for a belief to be rational one must not reliably suspend judgment about whether such a belief is reliable. ${ }^{23}$ Since reliably believing or suspending judgment about whether one's belief was reliably formed plausibly involves some kind of awareness of the rationality-contributors for that belief, these requisites entail that in some circumstances awareness of one's rationality-contributors

22 "Some reliabilists will be inclined to strengthen the requirement for justification by adding a negative requirement, namely, that the agent not believe that her firstorder belief is unreliably caused (or - what is arguably more in keeping with the spirit of reliabilism - that the agent not reliably believe that her first-order belief is so-caused)" (Goldman and Beddor 2016).

${ }^{23}$ BonJour (1985, chap. 3) acknowledges this point. In discussing Armstrong's externalist proposal, he presents the cases of Casper and Maud, in which agents are aware of good evidence that their belief-forming processes are not reliable. In this cases, BonJour appeals to intuitions of arbitrariness from the subject's perspective in order to argue that the agent is not justified. From these cases he draws the following lesson: "Cases like these two suggest the need for a further modification of Armstrong's account: in addition to the law-like connection between belief and truth and the absence of reasons against the particular belief in question, it must also be the case that the believer in question has no cogent reasons, either relative to his own situation or in general, for thinking that such a law-like connection does not exist, that is, that beliefs of that kind are not reliable." (BonJour 1985, p. 40) Then BonJour adds "Up to this point the suggestive modifications of Armstrong's criterion are consistent with the basic thrust of externalism as a response to the regress problem. What emerges is in fact a significantly more plausible externalist position." (BonJour 1985, p. 41). In other words, according to BonJour one might endorse the externalist claim that being reflectively aware of one's rationality-contributors is not a necessary condition for rationality (a belief can be rational even if what makes it rational is beyond one's ken) but still maintain that rationality requires that one does not have reasons to believe that one's belief is irrational (or I would like to add, suspend judgment about whether one's belief is rational). Admittedly, BonJour argues that the same kind of intuitions of arbitrariness arise in Norman's case, a case in which the subject is not aware that his belief-forming processes are reliable. Of course, the externalist will not follow BonJour in this last step. But nor do I need to follow BonJour there in order to maintain my present view. 
might have an impact on rationality. However, reliabilism is still an externalist view. The negative requirement that one is not aware of one's belief being unreliable, or that one doesn't suspend judgment about the matter, does not entail the positive requirement that one $i s$ aware of one's belief being reliable.

Something analogous might be said about the subject's perspective objection. In arguing for my view, I claimed that being aware of the rationality-contributors for one's belief and rationally suspending judgment about whether they make the belief rational will make such belief look accidental or arbitrary from one's perspective, thus making it doxastically irrational. Admittedly, the appeal to the perspective of the subject gives to the argument an internalist appearance. However, from what I have claimed in the previous section it doesn't follow that when you are not aware of the rationality-contributors for your belief and you have not reflected on the epistemic status of your first-order belief such belief will look accidental or arbitrary from your perspective, thus being irrational.

To better see the point, consider one frequently cited motivation for externalism. We are willing to grant justification to some beings, like small children, that do not have the cognitive resources to be reflectively aware of the rationality-contributors for their beliefs or to reflect on the epistemic status thereof. However, arguably a small child's belief that there is an object before him will not look accidental or arbitrary to him. So it doesn't seem to be true in general that the lack of awareness of one's reasons makes one's belief look accidental or arbitrary from one's own perspective. However, cases of moderate epistemic akrasia are very much unlike the one just mentioned. In cases of moderate epistemic akrasia the subject is in fact reflectively aware of (at least some of) the rationality-contributors for her belief and she has adopted a particular attitude concerning their epistemic status, i.e. suspension of judgment. In these cases in which there is in fact reflective awareness it is much less obvious, and I think counterintuitive, to say that the subject's belief will not look accidental or arbitrary to her. If a subject is reflectively aware that she is not able to determine whether her evidence supports her belief then it seems that forming or maintaining such belief will look arbitrary to her, in the sense that she is aware that she is treating her reasons as being indicative of the truth of her belief even though she believes that she is not able to determine whether they are. But the most important point is this: it is consistent to maintain that being aware of one's reasons and suspending judgment about the epistemic 
status of one's belief could make one's belief look accidental or arbitrary from one's perspective while rejecting that the same is so in cases in which one is not aware of his own reasons or has not reflected upon the epistemic status of his own belief. So my view is consistent with rejecting the subject's perspective objection: I do not need to maintain that if a subject is not aware of the rationality-contributors for her belief then the belief will look accidental or arbitrary to her; I need only maintain that in cases in which the subject $i s$ reflectively aware that she is not in a position to determine whether her evidence supports her belief, her belief will look accidental or arbitrary to her.

So my view presupposes neither the awareness requirement nor the subject's perspective objection. Since these theses characterize internalism, we can conclude that my view does not presuppose internalism.

There is a related worry worth considering. Even granting that my view does not presuppose internalism, one might argue that it does presupposes mentalism (Conee and Feldman 2004) - assuming that mentalism is not a form of internalism (Bergmann 2006, pp. 49-57). Let's follow Bergmann in characterizing mentalism as follows:

Mentalism: A belief's justification is a function solely of (i) which mental states the subject is in and (ii) which mental states of the subject the belief is based on. (I.e. if two possible subjects are exactly alike mentally and in terms of which of their mental states their beliefs are based on, then they are exactly alike justificationally.) (2006, p. 45)

Again, if this were correct my arguments would be very limited in their scope: anyone who believes that mentalism is false would remain unconvinced. Since mentalism is a controversial view, this is a legitimate worry. I will argue, however, that my view does not presuppose mentalism. First, it is important to note that rejecting mentalism is consistent with maintaining that sometimes a belief's rationality depends on some of the mental states the subject is in. The idea that not only mental states can be rationality-contributors does not entail that no mental state can be a rationality-contributor. Now, in the previous sections I argued that in the cases in which you suspend judgment about the epistemic status of your first-order belief, that belief is not doxastically rational. This presupposes that some mental states, e.g. some of the attitudes you hold towards the rationality-contributors for your belief, are relevant to the rationality of that belief. But this in no way entails that only mental states are relevant to determine the rationality of a belief. It is consistent 
to maintain that more than just mental states can play the role of rationality-contributors for a belief while contending that sometimes some mental states can affect one's belief rationality. If what I said is on the right track, my view does not presuppose mentalism neither.

To end this section, allow me a final remark in order to dissipate the worries that my argument is not sufficiently general. Let's call $X$ whatever property confers epistemic rationality on a belief. A moderately akratic agent is someone who believes $p$ and suspends judgment about whether her belief that $p$ has $X$. Of course, a rational moderately akratic agent is someone whose attitude of suspension of judgment is rational, i.e. someone whose attitude of suspension of judgment has property $X$. Now, put in these general terms, my argument in section 4 was that someone who rationally suspends judgment concerning whether her belief that $p$ possesses property $X$ and still maintains her belief that $p$ is being doxastically irrational, on account of being arbitrary. The arbitrariness stems from the fact that the subject believes that $p$ despite being committedly undecided concerning whether $p$ has $X$. In other words, the agent is aware that rationality dictates being undecided concerning whether her belief possesses rationality-conferring properties, but still she goes on believing as if her belief possessed such properties. Admittedly, in the cases at hand her belief has, by stipulation, rationality-conferring properties, but the point is that she cannot rationally take this for granted while being rationally undecided regarding whether that is actually the case.

It should be clear then that the argument can be formulated in general, my point being just that whatever you think of the merits of this argument, its success does not depend on any particular view on epistemic rationality.

\subsection{Perspective}

There is a third worry that needs to be addressed. Even granting that my view does not presuppose the subject's perspective objection, one might wonder why, in the cases at hand, one should grant such importance to the subject's perspective. Why should the believer's perspective have this kind of authority?

One way of putting the worry is the following. One might argue that all that matters to doxastic rationality is being sensitive to the evidence that makes one's belief propositionally rational. In discussing cases of radical epistemic akrasia, Coates presents the case of Huck and Jim: ${ }^{24}$

${ }^{24}$ The case was originally presented by Arpaly (2000). 
Huck accepts that slaves are property and believes he should turn Jim in to the authorities. But when the opportunity arises, he finds he cannot bring himself to do so and continues to help Jim escape. Like Bob, he judges his action to be morally wrong, even though it is in fact morally right. (Coates 2012, p. 116)

It might be tempting to argue that Huck's actions are subjectively blameworthy, since he believes that acting as he does is morally wrong. However, Coates argues that Huck's action is morally praiseworthy because the properties that motivate him to act as he does are the same that make his action morally right. In other words, his action responds to the right sort of moral properties even if his second-order moral belief does not. That is all we need in order to say, in Coates' words, that "he genuinely cares about morality". Analogously, one could say that in cases of moderate epistemic akrasia all that matters to the subject being doxastically rational is that the properties that motivate her in forming or sustaining her belief are the same that make the belief propositionally rational; if her belief responds to the right sort of epistemic properties then her belief is doxastically rational. If this is on the right track the perspective of the subject seems irrelevant: as long as she is sensitive to the properties that make her belief propositionally rational we could say that she really "cares" about forming rational beliefs.

The problem with this view, I think, is that it cannot make sense of cases of improper basing. To be sure, the reasons that motivate Mr. F.A. Lacy to form the belief that the Spurs will win are the same that make that belief propositionally rational for him. Still, his beliefs do not seem to be doxastically rational at all. As Turri notes, there is something wrong with the way in which those subjects perform in making use of their reasons. The whole point here is that being doxastically rational is not just about being motivated by the reasons that make a belief propositionally rational, it is also necessary that the subject's use of those reasons is competent.

Once it is acknowledged that proper basing is important, it becomes clearer that there is a place for arguing that the subject's perspective might also be important in the cases at hand. One might argue that a change in one's perspective might affect whether one's epistemic performance is appropriate, thereby affecting doxastic rationality. To better see the point, consider the following. Arguably, forming true beliefs and avoiding forming false ones are two important epistemic goals. Following the evidence is the right thing to do because by doing it we (are supposed to) attain those goals. Now, 
in cases of moderate epistemic akrasia the subject is committedly undecided about whether her evidence is indicative of the truth of her belief. It's not just that she is not aware of her evidence being indicative of the truth of her belief: she is rationally committed to the idea that she is not able to determine whether her evidence is in fact indicative of the truth of her belief —or in other words: she is rationally committed with the idea that the evidence equally supports the belief and its rejection. Still, she treats her evidence as if it were indicative of the truth of her belief. Treating evidence that one rationally believes is not indicative of the truth of a belief as being indicative of the truth of a belief shows some kind of epistemic incompetence, in the following sense: behaving like that can only mean either that $i$ ) the subject does not care about forming true beliefs and avoiding forming false ones, or $i$ i) she does care about forming true beliefs and avoiding false ones, but she is trying to attain those goals by ignoring the evidence, just by guessing and hoping to get lucky or iii) she is letting non-epistemic reasons play a role in belief-formation. In any of these cases, it is clear that the subject "does not care" about epistemic rationality.

\subsection{Forming vs. Sustaining a Belief}

There is a final worry we need to discuss. ${ }^{25}$ Consider the following possible case:

SLEePy Detective**: Sam is a police detective, working to identify a jewel thief. He knows he has good evidence —out of the many suspects, it will strongly support one of them. One day, very late at night, he is getting ready to go through the evidence. Before assessing the evidence, however, he calls his partner Alex to discuss the case. In that conversation Alex says to him: "Try not to go through the evidence now so late at night. Five times out of the last ten, your late-night reasoning has been quite sloppy. You're always very confident that you've found the culprit, but you were only half of the time right about what the evidence supported. So if you assess the evidence now there would be only a $50 \%$ chance your evidence supports your belief." Though Sam hadn't attended to his track record before, he rationally trusts Alex and believes that she is right, that is, that he is right only $50 \%$ of the times about what the evidence

\footnotetext{
${ }^{25}$ Thanks to a referee for Crítica for drawing my attention to this potential problem.
} 
supports on occasions of late-night reasoning. However, he does not follow her advice and assesses the evidence anyway. Now, since Sam trusts Alex, before going through the evidence he rationally suspends judgment about whether his evidence will support his belief. Later, after hours spent assessing all the evidence, he finally comes to the conclusion that Lucy is the thief. Sam is quite confident that his evidence points to Lucy's guilt, and he is quite confident that Lucy committed the crime. In fact, he has accommodated his evidence correctly, and his belief is rational.

This case is similar to Sleepy Detective* but it has one important difference, viz. Sam assesses his first-order evidence and forms his belief after he rationally suspends judgment about whether his evidence will support his future belief. The worry is that there may be important differences between Sleepy Detective** and Sleepy Detective*. One might feel that even if it is not doxastically rational to form a belief when one has rationally suspended judgment about whether one's belief will be supported by the evidence, it is doxastically rational to maintain a belief one already has in the face of rational suspension of judgment about whether one's evidence supports the belief.

The question then arises: What differentiates the case of forming a belief from the case of maintaining a belief? One possible answer appeals to epistemic conservatism — see Harman 1986, Foley 1983, Lycan 1988, Sklar 1975-. Roughly, epistemic conservatism's main thesis contends that the mere fact of holding a belief confers some degree of justification on that belief. As Vahid (2004) has noted, however, epistemic conservatism is not a unified view but a collection of related theses that have been defended by different philosophers. He distinguishes three different forms of epistemic conservatism:

Generation Conservatism (GC): Holding a belief is sufficient for its justification.

Perseverance Conservatism (PC): One should stop believing a proposition whenever one positively believes one's reasons for believing that proposition are not good.

Differential Conservatism (DC): One is justified in holding to a hypothesis (belief) despite coming to know of evidentially equivalent alternatives. (Vahid 2004, p. 102) 
From these options, differential conservatism (DC hereinafter) might provide a reason for sustaining that Sam can rationally maintain his belief that Lucy is guilty in a case like Sleepy Detective* but he cannot rationally form the belief that Lucy is guilty in Sleepy Detective**. ${ }^{26} \mathrm{DC}$ contends that an agent need not reject a hypothesis, once the hypothesis is believed, just because she comes to know of an evidentially equivalent alternative to it. In other words, according to DC "if an agent believes $p$ on the basis of evidence $E$, he is justified in believing that $p$ despite coming to recognize that an incompatible hypothesis, $q$, is equally supported by $E$ " (Vahid 2004, p. 103). Now, the arguments provided in the previous paragraphs maintain that holding a belief in the face of moderate epistemic akrasia would be arbitrary. Roughly, this is because in those cases, from the subject's perspective both believing $p$ and believing $\sim p$ look to be equally supported by the evidence. But here a defender of epistemic conservatism might object that the arguments only work in cases of belief formation. If the subject already holds the belief when she rationally suspends judgment in the second level she should not abandon it, since the situation looks from the subject's perspective like one in which DC applies: one should not abandon a belief just because one acknowledges that there is an incompatible belief that enjoys an equally strong support from the evidence.

This objection depends on whether DC is correct. But there are reasons to reject DC. ${ }^{27}$ First, one might press the charge of arbitrariness against DC itself. If the subject thinks that both $p$ and $\sim p$ are equally likely in light of her evidence, why would the mere fact that she happened to form the belief that $p$ first make a difference? The belief that $\sim p$ could have had the same epistemic status had the agent formed that belief first. But plausibly the facts that determine that a subject forms one belief before another are not epistemically relevant. So it just seems arbitrary to confer a privileged epistemic status to a belief just because it was produced at an earlier time.

However, I find Vahid's argument the most compelling. The problem is that DC contravenes the thesis of epistemic supervenience according to which the justification of a belief supervenes on certain non-epistemic properties of that belief (e.g., being part of a coherent belief system, being reliably produced, being adequately grounded, etc.). A consequence of that thesis is that if two beliefs share the

\footnotetext{
${ }^{26}$ See Sklar 1975 for a defense of this kind epistemic conservatism.

${ }^{27}$ See Christensen 1994 for discussion.
} 
same subvening property and one is justified, so is the other. Now, consider the following:

Suppose now two scientists $S_{1}$ and $S_{2}$ who, faced with the task of explaining the same data, come up with incompatible but evidentially equivalent hypotheses $H_{1}$ and $H_{2}$ respectively. Suppose further that the hypotheses in question become known to both some time later during a meeting where $S_{2}$, for some reason of his own, gives up $H_{2}$ and follows $S_{1}$ in believing $H_{1}$. Now, according to DC, $S_{2}$ should have stuck with $H_{2}$. His belief that $H_{1}$ is, thus, unjustified while $S_{1}$ is justified in believing $H_{1}$ and rejecting $H_{2}$. So, assuming that DC is normatively correct, we are faced with a situation in which while believing $H_{1}$ is rational (justified) for $\mathrm{S}_{1}$, another token of the same belief fails to be rational (justified) for $S_{2}$ despite the two tokens sharing the same subvening justification-conferring property, and this contravenes the thesis of epistemic supervenience. (Vahid 2004, p. 105)

As Vahid also notes, we could understand the objection from arbitrariness not in terms of the time at which the belief was formed but in terms of the supervenience thesis: a subject that behaves in accordance with DC is prepared to ascribe the property of justification or rationality to one belief while refraining from treating another belief as justified or rational despite the fact that both beliefs seem to him to share the same subvening justification-conferring property, and this "introduces an element of arbitrariness into our canons of rationality" (Vahid 2004, p. 106).

So appealing to epistemic conservatism in order to defend that there are cases of rational moderate epistemic akrasia, viz. those involving the sustaining of a belief, faces its own problems. There might be other strategies available in order to defend this view, but I think in this case the onus of proof is on my potential opponents.

\section{Conclusion}

The thesis I have defended concerns doxastic rationality in cases of moderate epistemic akrasia. I argued that, given an attitudinal account of suspension of judgment, a moderately akratic agent is doxastically irrational. The reason is, roughly, that such an agent does not base her belief properly.

To conclude, it's important to note that my position is prima facie consistent both with the view maintained by Feldman (2005), Huemer (2011) and Bergmann (2005), according to which moderate epistemic akrasia is never rational in the propositional sense, and the 
position sustained by Hazlett (2012), who claims the opposite. On the one hand, my position is compatible with the former view: since propositional rationality is a necessary condition for doxastic rationality, if there are no possible circumstances in which an agent has propositional rationality for being moderately akratic then moderate epistemic akrasia is not doxastically rational. On the other hand, my position is compatible with Hazlett's view. That view states that there are cases of rational moderate epistemic akrasia in the propositional sense, but says nothing concerning doxastic rationality. There is no reason, prima facie, to assume that it is always possible to rationally hold the attitudes that it is rational for one to hold: it could be that in some cases it is rational to suspend judgment about whether it is rational to believe $p$ and it is rational to believe $p$, but still one could not rationally hold that combination of attitudes.

Some might find the latter view odd. It seems that if it is rational for you to hold an attitude then were you to adopt it, you would be rationally holding that attitude. What could it mean that it is rational for you to believe $p$, but were you to believe $p$ you would not believe it rationally?

This "oddness" should not be surprising, though. As LasonenAarnio points out, cases of conflicting higher-order evidence seem to present a puzzle: "The puzzle is that at least in some situations involving higher-order defeaters the correct epistemic rules issue conflicting recommendations. For instance, a subject ought to believe $p$, but she ought also to suspend judgment in $p$ " (Lasonen-Aarnio 2014, p. 314). Putting aside considerations about whether higher-order evidence really constitutes a defeater, this is what seems to be at stake in cases of moderate epistemic akrasia: first-order evidence supports believing $p$ but, apparently, higher-order evidence also supports suspending judgment about $p$ (indirectly, by providing evidence that one's firstorder evidence does not support $p$, or that one's belief is the result of a flawed cognitive process, etc.) Ideally, epistemic rationality mandates that one follows both first-order and higher-order evidence, but in this case they seem to make conflicting recommendations. One possible response, the one that is endorsed by defenders of rational akrasia, is to deny that higher-order evidence supports suspending judgment about the first-order belief in these cases. According to this view, in the cases at hand first-order evidence makes it rational to believe $p$ and higher-order evidence makes it rational to suspend judgment about whether it is rational to believe $p$. Most importantly, higher-order evidence does not make it rational to suspend judgment about $p$ itself. Since according to this view the two levels are to 
some extent independent, i.e. the higher-level does not affect the rationality (whether propositional or doxastic) of the first-order level belief; you can rationally believe $p$ and rationally suspend judgment about $p$ without thereby incurring in an epistemic fault.

But there is another possibility, viz. to embrace the idea that there are genuine epistemic dilemmas. Like Christensen, one could endorse the view that higher-order evidence is sometimes Rationally Toxic, that is, that sometimes higher-order evidence "may put agents in a position where the most rational response to their total evidence violates some rational ideal" (Christensen 2014, p. 2). The second view described above, viz. the view that accepts that moderate epistemic akrasia is propositionally rational but rejects that it is doxastically rational, is in line with this insight: sometimes higher-order evidence puts you in a position in which you cannot rationally believe what is rational for you to believe.

\section{REFERENCES}

Alston, W.P., 1980, "Level-Confusions in Epistemology", Midwest Studies In Philosophy, vol. 5, pp. 135-150.

Arpaly, N., 2000, “On Acting Rationally Against One's Best Judgment", Ethics, vol. 110, no. 3, pp. 488-513.

Audi, R., 1986, "Belief, Reason, and Inference", Philosophical Topics, vol. 14, no. 1, pp. 27-65.

Bergmann, M., 2006, Justification without Awareness: A Defense of Epistemic Externalism, Oxford University Press, place.

—_, 2005, "Defeaters and Higher-Level Requirements", The Philosophical Quarterly, vol. 55, no. 220, pp. 419-436.

BonJour, L., 1985, The Structure of Empirical Justification, Harvard University Press, Cambridge, Mass.

Christensen, D., 2014, "Conciliation, Uniqueness and Rational Toxicity", Noûs, vol. 50, no. 3, pp. 584-603.

— , 2010, "Higher-Order Evidence", Philosophy and Phenomenological Research, vol. 81, pp. 185-215.

— 2007, "Does Murphy's Law Apply in Epistemology? Self-Doubt and Rational Ideals", in T. Szabó Gendler and J. Hawthorne, Oxford Studies in Epistemology, vol. 2, Oxford University Press, New York, 2007, pp. 3-31. 89.

Coates, A., 2012, "Rational Epistemic Akrasia", American Philosophical Quarterly, vol. 49, no. 2, pp. 113-124. 
Conee, E., y R. Feldman., 2004, Evidentialism: Essays in Epistemology, Clarendon Press, Oxford.

Crawford, S., 2004, "A Solution for Russellians to a Puzzle about Belief", Analysis, vol. 64, no. 3, pp. 223-229.

Feldman, R. 2005, "Respecting the Evidence", Philosophical Perspectives, vol. 19, no. 1, pp. 95-119.

—_, 2000, "The Ethics of Belief", Philosophy and Phenomenological Research, vol. 60, no. 3, pp. 667-695.

Foley, R., 1983, "Epistemic Conservatism", Philosophical studies, vol. 43, no. 2, pp. 165-182.

Friedman, J., 2013, "Suspended Judgment", Philosophical Studies, vol. 162, no. 2, pp. 165-181.

Goldman, A., and B. Beddor, 2016, "Reliabilist Epistemology", The Stanford Encyclopedia of Philosophy (Winter 2016 edition), E.N. Zalta (ed.), available at: < https://plato.stanford.edu/archives/win2016/entries/ reliabilism/> [accessed: 04/10/2017].

Greco, D., 2013, "A Puzzle about Epistemic Akrasia", Philosophical Studies, vol. 167, no. 2, pp. 201-219.

Harman, G., 1986, Change in View, MIT Press, Cambridge, Mass.

Hazlett, A., 2012, "Higher-Order Attitudes and Epistemic Humillity", Episteme, vol. 9, no. 3, pp. 205-223.

Horowitz, S., 2014, "Epistemic Akrasia", Nô̂s, vol. 48, no. 4, pp. 718-744.

Huemer, M., 2011, "The Puzzle of Metacoherence", Philosophy and Phenomenological Research, vol. 82, no. 1, pp. 1-21.

Lasonen-Aarnio, M., 2014, "Higher-Order Evidence and the Limits of Defeat", Philosophy and Phenomenological Research, vol. 88, no. 2, pp. 314-345.

Lycan, W.G., 1988, Judgement and Justification, Cambridge University Press, Cambridge.

McCain, K., 2012, "The Interventionist Account of Causation and the Basing Relation", Philosophical Studies, vol. 159, no. 3, pp. 357-382.

Moser, P.K., 1991, Knowledge and Evidence, Cambridge University Press, Cambridge.

Silva, P., 2015, "On Doxastic Justification and Properly Basing One's Beliefs", Erkenntnis, vol. 80, no. 5, pp. 945-955.

Sklar, L., 1975, "Methodological Conservatism", The Philosophical Review, vol. 84, no. 3, pp. 374-400.

Smithies, D., 2012, "Moore's Paradox and the Accessibility of Justification", Philosophy and Phenomenological Research, vol. 85, no. 2, pp. 273-300.

Titelbaum, M.G., 2015, "Rationality's Fixed Point (Or: In Defense of Right Reason)", in T. Szabó Gendler and J. Hawthorne, Oxford Studies in Epistemology, vol. 5, Oxford University Press, Oxford, 2015, pp. 253292; also available at Oxford Scholarship Online (doi: 10.1093/acprof:oso/ 9780198722762.003.0009). 
Tolliver, J., 1982, "Basing Beliefs on Reasons", Grazer Philosophische Studien, vol. 15, pp. 149-161.

Turri, J., 2011, "Believing for a Reason", Erkenntnis, vol. 74, no. 3, pp. 383-397.

—_ 2010, "On the Relationship between Propositional and Doxastic Justification", Philosophy and Phenomenological Research, vol. 80, no. 2, pp. 312-326.

Vahid, H., 2004, "Varieties of Epistemic Conservatism", Synthese, vol. 141, no. 1, pp. 97-122.

Weatherson, B., unpublished ms. (2010), "Do Judgments Screen Evidence?", available at: $<$ http://brian.weatherson.org/JSE.pdf $>$ [consulted: $15 / 12 / 2017]$.

Wedgwood, R., 2012, "Justified Inference", Synthese, vol. 189, no. 2, pp. 273-295.

Received: September 24, 2016; revised: August 18, 2017; accepted: December 15, 2017. 